\title{
Role of biologics and biosimilars in inflammatory bowel disease: current trends and future perspectives
}

This article was published in the following Dove Press journal: Journal of Inflammation Research

\author{
Prashanth Rawla' \\ Tagore Sunkara ${ }^{2}$ \\ Jeffrey Pradeep Raj ${ }^{3}$ \\ 'Department of Internal Medicine, \\ Memorial Hospital of Martinsville \\ and Henry County, Martinsville, VA, \\ ${ }^{2}$ Division of Gastroenterology and \\ Hepatology, The Brooklyn Hospital \\ Center, Clinical Affiliate of The Mount \\ Sinai Hospital, New York, NY, USA; \\ ${ }^{3}$ Department of Pharmacology, St \\ John's Medical College, Bangalore, \\ India
}

\begin{abstract}
Inflammatory bowel disease (IBD) is an idiopathic chronic inflammatory disease of the gastrointestinal system. The spectrum is of predominantly two types, namely, ulcerative colitis and Crohn's disease. The incidence of IBD has been increasing steadily since 1990, and so the number of agents used in their treatment. Biologics that are derived partly or completely from living biological sources such as animals and humans have become widely available, which provide therapeutic benefits to the IBD patients. Currently, monoclonal antibodies against tumor necrosis factor-alpha (infliximab, adalimumab, certolizumab, and golimumab), integrins (vedolizumab and natalizumab), and interleukin (IL)-12 and IL-23 antagonists (ustekinumab) are approved for use in IBD. Biosimilars of infliximab and adalimumab are also available for the treatment of IBD. This review summarizes the clinical pharmacology, studies leading to their approval, overall indications and their use in IBD, usage in pregnancy and lactation, and the adverse effects of these agents. This review also summarizes the recent advances and future perspectives specific to biologics and biosimilars in IBD.

Keywords: inflammatory bowel disease, Crohn's disease, ulcerative colitis, biologics, biosimilars, tumor necrosis factor, integrin, interleukin, adalimumab, Humira ${ }^{\circledR}$, certolizumab, Cimzia ${ }^{\circledR}$, golimumab, Simponi ${ }^{\circledR}$, infliximab, Remicade ${ }^{\circledR}$, vedolizumab, Entyvio, natalizumab, Tysabri ${ }^{\circledR}$, ustekinumab, Stelara ${ }^{\circledR}$
\end{abstract}

\section{Introduction}

The inflammatory bowel disease (IBD) comprises two types, namely, the ulcerative colitis (UC) and Crohn's disease (CD). They are a spectrum of chronic idiopathic autoimmune inflammatory disorders with remission and relapses, primarily affecting the gastrointestinal system. ${ }^{1}$ It was traditionally regarded as the disease of the westernized nations, but in the 21 st century, the epidemiology of IBD is fast changing. ${ }^{2}$ A systematic review reports that the highest prevalence of IBD is seen in Europe (UC 505 per 1,00,000 in Norway and CD 322 per 1,00,000 in Germany) and North America (UC 286 per 1,00,000 in the USA and CD 319 per 1,00,000 in Canada). ${ }^{3}$ It also reports that the incidence has been rising since 1990 in newly industrialized countries of Africa, Asia, and South America. For example, the annual percentage change of UC and CD in Brazil was $+14.9 \%$ (95\% CI 10.4, 19.6) and $+11.1 \%(95 \%$ CI $4.8,17.8)$, respectively, whereas in Taiwan, it was $+4.0 \%(95 \%$ CI $1.0,7.1)$ and $+4.8 \%\left(95 \%\right.$ CI 1.8, 8.0), respectively. ${ }^{3} \mathrm{UC}$ is characterized by confluent mucosal inflammation and erosions starting from the anal verge and extending to a variable extent. ${ }^{4} \mathrm{CD}$ is a transmural inflammation of any part of the gastrointestinal tract with
Correspondence: Tagore Sunkara Division of Gastroenterology and Hepatology, The Brooklyn Hospital Center, Clinical Affiliate of The Mount Sinai Hospital, I2I Dekalb Avenue, Brooklyn, NY I I20I, USA

$\mathrm{Tel}+\mathrm{I} 21767 \mid 2094$

Fax +17182508120

Email tagoresunkara@hotmail.com 
characteristic rectal sparing and skip lesions often associated with extraintestinal manifestations involving the joint, skin, or eyes. ${ }^{5}$ Patients often complain of diarrhea associated with rectal bleeding, abdominal tenderness, and weight loss. ${ }^{6,7}$

Etiopathogenesis of IBD comprises genetic components, environmental factors, microbial flora of the gut, and immune responses. ${ }^{8}$ However, the main mechanism seems to be the bacterial antigens gaining access to the antigenpresenting cells through the impaired epithelial barrier. There are interleukin (IL)-12- and IL-18-mediated type 1 helper T-cell responses in CD and IL-4-mediated type 2 helper T-cell responses in UC. ${ }^{9}$ The balance between proand anti-inflammatory responses is governed by regulatory $\mathrm{T}_{\mathrm{H}} 17$ and $\mathrm{T}_{\text {req }}$ cells as both of them serve to limit immune and inflammatory responses in the gut. ${ }^{9}$ The $\mathrm{T}$ cells further govern the release of IFN and tumor necrosis factor (TNF) that recruit macrophages, which in turn positively regulate T helper cells. ${ }^{9}$ Finally, the recruited inflammatory cells gain access to the site of inflammation with the help of cell adhesion molecules such as integrins. ${ }^{9}$

Medical therapy of IBD is complex as the disease etiology is multifactorial and the primary aim of pharmacotherapy is to dampen the generalized inflammatory response, thereby relieving symptoms. ${ }^{10}$ Off late importance has been given to mucosal healing as well. ${ }^{10}$ The specific goals of treatment in IBD include the control of acute exacerbation, maintenance of relapses, treatment of specific complications, and surveillance of malignant transformation. ${ }^{11}$ Traditionally, the drugs used in the treatment of IBD are mesalamine derivatives (mesalamine, sulfasalazine, olsalazine, and balsalazide), glucocorticoids (prednisolone, methylprednisolone, hydrocortisone, and budesonide), and immunomodulators (6-mercaptopurine, azathioprine, methotrexate, cyclosporine, and tacrolimus). ${ }^{10}$ With the advent of advances in medical science and technology, a new group of drugs emerged for various chronic disease conditions called the biologics that are derived partly or completely from living biological sources such as animals and humans. ${ }^{12}$ The most widely used biologics are the TNF- $\alpha$ inhibitors such as adalimumab, certolizumab, golimumab, and infliximab, which are highly effective in the treatment of both UC and CD. The other biologic agents in IBD include the integrin receptor antagonists, namely, vedolizumab and natalizumab, and IL-12 and IL-23 antagonist, ustekinumab. ${ }^{13}$ This review summarizes the clinical pharmacology, overall indications and their use in IBD, usage in pregnancy and lactation, and the adverse effects of these agents and their biosimilars.

We have summarized various approved agents for current use in IBD and their recommended dosage regimen in Table 1. Some of the biologics in the Phases II and III of their development along with their mechanism of action as registered in the global clinical trial registry (www.clinicaltrials. gov) for use in IBD are summarized in Table 2. Similarly, the biosimilars in the pipeline at various stages of development for use in IBD and their status in various countries of the world are summarized in Table 3.

Table I Summary of biologics and biosimilars approved for treatment in IBD

\begin{tabular}{|c|c|c|c|c|c|}
\hline \multirow{2}{*}{$\begin{array}{l}\text { Name (innovator agent/ } \\
\text { biosimilar) }\end{array}$} & \multirow[t]{2}{*}{ Brand name (company) } & \multirow{2}{*}{$\begin{array}{l}\text { IBD } \\
\text { indication }\end{array}$} & \multirow{2}{*}{$\begin{array}{l}\text { Route of } \\
\text { administration }\end{array}$} & \multicolumn{2}{|l|}{ Dosage regimen } \\
\hline & & & & Induction & Maintenance \\
\hline Adalimumab (innovator) & Humira $^{\circledR}($ AbbVie $)$ & $\mathrm{UC}$ and $\mathrm{CD}$ & SC & $160 \mathrm{mg}$ on day I and & $40 \mathrm{mg}$ every 4 weeks \\
\hline Adalimumab-atto (biosimilar) & Amjevita TM (Amgen) & & & $80 \mathrm{mg}$ on day 15 & from day 29 \\
\hline Adalimumab-adbm (biosimilar) & Cyltezo $^{\circledR}$ (Boehringer Ingelheim) & & & & \\
\hline Certolizumab pegol (innovator) & Cimzia $^{\circledR}$ (Union ChimiqueBelge) & $C D$ & SC & $\begin{array}{l}400 \mathrm{mg} \text { at weeks } 0 \text {, } \\
2 \text {, and } 4\end{array}$ & $\begin{array}{l}200 \mathrm{mg} \text { 2-weekly/400 mg } \\
\text { 4-weekly }\end{array}$ \\
\hline Golimumab (innovator) & Simponi ${ }^{\circledR}$ (Janssen Biotech) & UC & SC & $\begin{array}{l}200 \mathrm{mg} \text { at week } 0 \text { and } \\
100 \mathrm{mg} \text { at week } 2\end{array}$ & $100 \mathrm{mg}$ every 4 weeks \\
\hline Infliximab (innovator) & Remicade ${ }^{\circledR}$ (Janssen Biotech) & $\mathrm{UC}$ and $\mathrm{CD}$ & IV & $5 \mathrm{mg} / \mathrm{kg}$ IV at weeks 0 & $5 \mathrm{mg} / \mathrm{kg}$ every 8 weeks \\
\hline Infliximab-dyyb (biosimilar) & Inflectra ${ }^{\circledR}$ (Celltrion) & & & 2 , and 6 (in $C D$ alone & \\
\hline Infliximab-qbtx (biosimilar) & Ixifi $^{\mathrm{TM}}$ (Pfizer) & & & I0/kg may be given) & \\
\hline Infliximab-abda (biosimilar) & Renflexis ${ }^{\mathrm{TM}}$ (Merck) & & & & \\
\hline Vedolizumab (innovator) & $\begin{array}{l}\text { Entyvio }^{\circledast} \text { (Takeda } \\
\text { Pharmaceuticals) }\end{array}$ & $U C$ and $C D$ & IV & $\begin{array}{l}300 \mathrm{mg} \text { at weeks } 0 \text {, } \\
2 \text {, and } 6\end{array}$ & $300 \mathrm{mg}$ every 8 weeks \\
\hline Natalizumab (innovator) & Tysabri $^{\circledast}$ (Biogen) & $C D$ & $\begin{array}{l}\text { IV infusion over } \\
\text { I hour }\end{array}$ & $300 \mathrm{mg}$ every 4 weeks & \\
\hline Ustekinumab (innovator) & Stelara ${ }^{\circledR}$ (Janssen Biotech) & $C D$ & $\begin{array}{l}\text { IV for induction } \\
\text { SC for } \\
\text { maintenance }\end{array}$ & $\begin{array}{l}\leq 55 \mathrm{~kg}=260 \mathrm{mg} \\
56-85 \mathrm{~kg}=390 \mathrm{mg} \\
>85 \mathrm{~kg}=520 \mathrm{mg}\end{array}$ & 90 mg every 8 weeks \\
\hline
\end{tabular}

Abbreviations: CD, Crohn's disease; IBD, inflammatory bowel disease; IV, intravenous; SC, subcutaneous; UC, ulcerative colitis. 
Table 2 Biologics in the pipeline and their current status

\begin{tabular}{llll}
\hline Serial number & Agent name & Mechanism of action & Current status \\
\hline I & Etrolizumab & $\alpha 4 \beta 7$ integrin antagonist & Phase III (UC and Crohn's disease) \\
2 & Risankizumab & IL-23 inhibitor & Phase III (Crohn's disease) \\
3 & Bertilimumab & Chemokine CCLII inhibitor & Phase II (Crohn's disease and UC) \\
4 & Bimekizumab & IL-I7 inhibitor & Phase II (UC) \\
5 & E60II & Chemokine CX3CLI inhibitor & Phase I/II (Crohn's disease) \\
6 & FFPI04 & CD40 antigen inhibitor & Phase II (UC) \\
7 & Foralumab & CD3 antigen inhibitor & Phase II (Crohn's disease) \\
8 & KHK4083 & OX40 receptor antagonist & Phase II (UC) \\
9 & Mirikizumab & IL-23 inhibitor & Phase II (Crohn's disease and UC) \\
I0 & PF0423692I & IL-6 inhibitor & Phase II (Crohn's disease) \\
II & SHP 647 & $\alpha 4 \beta 7$ integrin antagonist & Phase II (Crohn's disease) and Phase III (UC) \\
\hline
\end{tabular}

Abbreviations: $\mathrm{CCL}, \mathrm{C}-\mathrm{C}$ motif chemokine ligand; $\mathrm{CD}$, cluster of differentiation; $\mathrm{CX} 3 \mathrm{CL}, \mathrm{C}-\mathrm{X} 3-\mathrm{C}$ motif ligand; IL, interleukin; UC, ulcerative colitis.

Table 3 Biosimilars in the pipeline and their current status

\begin{tabular}{|c|c|c|}
\hline Company & Name of the agent & Status \\
\hline \multicolumn{3}{|l|}{ Biosimilars of adalimumab } \\
\hline Coherous Biosciences & $\mathrm{CHSI} 420$ & Phase III (plaque psoriasis) \\
\hline Fresenius Kabi & MSBII 022 & Preregistration (plaque psoriasis) and Phase III (UC, CD, and others) \\
\hline Fujifilm Kyowa Kirin Biologics & FKB327 & Preregistration (RA). Submitted to EMA in May 2017 \\
\hline LG Chem & LBAL & Phase III (RA) \\
\hline Momenta Pharmaceuticals & M923 & Phase III (RA and plaque psoriasis) \\
\hline Oncobiologics & ONS30I0 & Phase III (plaque psoriasis) \\
\hline Pfizer & PF064I0293 & Phase III (RA) \\
\hline Prestige BioPharma & PBPI502 & Preclinical (RA) \\
\hline Merck \& Samsung Bioepis & Imraldi & Registered (UC, CD, and others), EMA approved on June 23, 2016 \\
\hline Sandoz & GP20I7 & Preregistration (UC, CD, and others). Submitted to EMA in June 2017 \\
\hline Reliance Life Sciences & Adfrar & $\begin{array}{l}\text { Launched in India for UC, RA, plaque psoriasis, psoriatic arthritis, and ankylosing } \\
\text { spondylitis in January } 2016\end{array}$ \\
\hline Zydus Cadila & Exemptia & $\begin{array}{l}\text { Launched in India for UC, CD, RA, juvenile RA, plaque psoriasis, psoriatic arthritis and } \\
\text { ankylosing spondylitis, and hidradenitis suppurativa in December } 2014\end{array}$ \\
\hline \multicolumn{3}{|l|}{ Biosimilars of infliximab } \\
\hline Amgen & ABP7IO & Phase III (RA) and Phase I (UC, CD, and others) \\
\hline Epirus Biopharmaceuticals & Infimab & Launched in India for RA in September 2014 \\
\hline MabTech/Sorrento Therapeutics & STI002 & Phase III (RA) \\
\hline Nichi-lko Pharmaceutical & NI07I & Launched in Japan in September 2017. US Phase III trial in RA ongoing \\
\hline Nippon Kayaku & Infliximab BS & $\begin{array}{l}\text { Launched in Japan for UC, CD, RA, ankylosing spondylitis, plaque psoriasis, and psoriatic } \\
\text { arthritis in November } 2014\end{array}$ \\
\hline Reliance Life Sciences & BOW0I5 & Launched in India for RA in December 2014 \\
\hline Sandoz/Pfizer & PF-06438I79 & $\begin{array}{l}\text { Registered for UC, CD, RA, ankylosing spondylitis, plaque psoriasis, and psoriatic } \\
\text { arthritis. Submitted to FDA in May } 2017 \text { and EMA in June } 2017\end{array}$ \\
\hline
\end{tabular}

Abbreviations: CD, Crohn's disease; EMA, European Medicines Agency; FDA, US Food and Drug Administration; RA, rheumatoid arthritis; UC, ulcerative colitis.

\section{Review methodology}

Studies were searched in electronic databases according to article titles, abstract contents, and relevance in the field of biologics and biosimilars in IBD. The database used in this review included PubMed, MEDLINE, Embase, Google Scholar, Scopus, ClinicalTrials.gov, US Food and Drug Administration (FDA), European Medicines Agency, and Cochrane databases. We also manually searched references to identify additional relevant studies. The "Keywords" above were used to locate relevant journal articles. Here, we provide a comprehensive narrative literature review of the role of biologics and biosimilars in IBD as well as discuss and highlight the clinical pharmacology, overall indications and their use in IBD, usage in pregnancy and lactation, and the adverse effects of these agents and their biosimilars.

\section{Discussion}

\section{TNF- $\alpha$ inhibitors}

Adalimumab (Humira ${ }^{\circledR}$ )

Mechanism of action and indications

Adalimumab is the first fully human monoclonal antibody (MAb) that was approved by the FDA in 2002 for rheumatoid 
arthritis (RA). ${ }^{14}$ It was initially named as D2E7 marketed by Abbott Laboratories (Chicago, IL, USA) and currently owned by AbbVie (Chicago, IL, USA). ${ }^{15}$ The name Humira stands for human $\mathrm{MAb}$ in RA. It is a recombinant human immunoglobulin (Ig)-G1 MAb created using the phage display technology. ${ }^{16}$ It inhibits TNF- $\alpha$, which is a cytokine involved in normal inflammatory and immunological responses, and it inhibits its interaction with p55 and p75 cell surface TNF-alpha receptors. It does not have action on TNF-beta. ${ }^{16}$ It also causes changes in the levels of adhesion molecules that are responsible for leukocyte migration. Adalimumab is indicated for use in moderate-to-severe RA, juvenile idiopathic arthritis, psoriatic arthritis, ankylosing spondylitis, moderate-to-severe $\mathrm{CD}$ and $\mathrm{UC}$ with inadequate response to conventional therapy, moderate-to-severe chronic plaque psoriasis, hidradenitis suppurativa, uveitis, and Behcet's disease. ${ }^{17}$ It is available as a sterile, preservative-free solution in the pen of 80 and $40 \mathrm{mg}$, the prefilled syringes of 80, 40, 20, and $10 \mathrm{mg}$, and a single use institutional vial of $40 \mathrm{mg}$, which are to be given subcutaneously (SC). ${ }^{14}$ The bioavailability of the agent is $64 \%$ with a half-life of $\sim 2$ weeks following linear kinetics of elimination. ${ }^{14}$

\section{Dosing in CD}

The recommended dose regimen for use in $\mathrm{CD}$ in adults is $160 \mathrm{mg}$ on day $1,80 \mathrm{mg}$ on day 15 , and a maintenance dose of $40 \mathrm{mg}$ every alternate week starting at day 29 for not $>1$ year. ${ }^{14}$ The evidence for the use of adalimumab in CD stems from three main clinical trials, namely, CLASSIC (clinical assessment of adalimumab safety and efficacy studied as induction therapy in CD), CHARM (Crohn's trial of the fully human antibody adalimumab for remission maintenance), and GAIN (gauging adalimumab efficacy in infliximab nonresponders). ${ }^{18}$ The CLASSIC-I trial is a dose-ranging randomized controlled trial (RCT) with 299 moderate-to-severe CD patients naive to TNF- $\alpha$ inhibitor therapy who were randomized to receive adalimumab $(40 / 20,80 / 40$, or $160 / 80 \mathrm{mg})$ or placebo at weeks 0 and 2. The remission rates (primary endpoint) defined as $\mathrm{CD}$ activity index $(\mathrm{CDAI})<150$ at week 4 were $18 \%(P=0.36)$, $24 \%(P=0.06)$, and $36 \%(P=0.001)$, respectively, and $12 \%$ in the placebo group. ${ }^{19} \mathrm{~A}$ total of 275 patients from CLASSICI entered the CLASSIC-II RCT where all patients received $40 \mathrm{mg}$ adalimumab at weeks 4 and 6 of CLASSIC-I. A total of 55 patients who were at remission during both the dosing of CLASSIC-II were re-randomized into adalimumab $40 \mathrm{mg}$ every other week (EOW), weekly, or placebo through 56 weeks. The rates of remission were $79 \%, 83 \%$, and $44 \%$, respectively. The remaining 204 patients who were not on remission while entering CLASSIC-II were subjected to adalimumab $40 \mathrm{mg}$ EOW open label with the option to increase the dose to $40 \mathrm{mg}$ weekly in case of a nonresponse or flare, and at 56 weeks, $46 \%$ were at remission. ${ }^{20}$ In CHARM trial, $\sim 40 \%$ of the 499 patients with moderate-to-severe CD had clinical remission at 26 and 52 weeks suggesting long-term efficacy. ${ }^{21}$ In case of the GAIN trial conducted among patients who had either lost response or were intolerant to infliximab, patients were randomized to receive either adalimumab induction therapy or placebo and $21 \%$ achieved remission while approximately half demonstrated clinical benefit. ${ }^{22} \mathrm{~A}$ study done by Cote-Daigneault et al has shown the evidence for efficacy in fistulizing CD and in achieving mucosal healing in CD unlike certolizumab and in UC. ${ }^{23}$ Adalimumab is indicated in pediatric CD. IMAgINE 1 and IMAgINE 2 are the two trials showing the evidence of efficacy and safety of adalimumab in pediatric population. The IMAgINE 1 trial was conducted in 192 children with CD not responding to conventional therapy. After an open-label induction therapy with SC adalimumab at weeks 0 and 2, 188 children at week 4 were randomized to receive double-blind maintenance therapy with either high dose (40 or $20 \mathrm{mg}$ for body weight $\geq 40$ or $<40 \mathrm{~kg} ; \mathrm{n}=93$ ) or low dose ( 20 or $10 \mathrm{mg}$ for body weight $\geq 40$ or $<40 \mathrm{~kg}$; $\mathrm{n}=95$ ) of adalimumab alternate week for 48 weeks. At week 26, 63 (33.5\%) of the 152 patients who completed 26 weeks were in clinical remission. High- and low-dose groups (36/93 [38.7\%] versus 27/95 [28.4\%]) showed no significant difference $(P=0.075) .{ }^{24}$ Patients who completed IMAgINE 1 were eligible to enroll in IMAgINE 2. A total of 100 children participated for up to 240 weeks. A total of $41 \%$ and $48 \%$ achieved remission (pediatric CDAI $\leq 10$ ) and response (pediatric CDAI decrease $\geq 15$ from IMAgINE 1 baseline) at 240 weeks, respectively. The safety profile was similar to those in adult CD trials with adalimumab and IMAgINE 1 trial. $^{25}$

\section{Dosing in UC}

The recommended dose regimen for UC is $160 \mathrm{mg} \mathrm{SC}$ on day 1 (or $80 \mathrm{mg}$ on two consecutive days) followed by a dose of $80 \mathrm{mg}$ on day 15 and, 2 weeks later (day 29), continues with a dose of $40 \mathrm{mg}$ EOW. ${ }^{14} \mathrm{~A}$ meta-analysis of three RCTs reported that adalimumab 160/80 mg was more efficacious when compared with placebo for the induction of clinical remission (relative risk [RR] 1.62, 95\% CI 1.15, 2.29) and clinical response (RR 1.37, 95\% CI 1.19, 1.59). Similarly, adalimumab $40 \mathrm{mg}$ EOW was more effective than placebo in maintaining clinical remission (RR 2.38, 95\% CI 1.57, 3.59 ) and clinical response (RR 1.69, 95\% CI 1.29, 2.21). ${ }^{26}$ 


\section{Side effects}

The most serious adverse reactions encountered in clinical trials were serious infections due to immunosuppression, malignancies, and demyelinating neurological disease. ${ }^{14}$ Serious infections include pneumonia, septic arthritis, prosthetic/postsurgical infections, erysipelas, cellulitis, diverticulitis, and pyelonephritis at an incidence rate of 0.04 /patient-year (PY) when compared with $0.02 / \mathrm{PY}$ in the placebo arm. ${ }^{14}$ The most frequently encountered malignancies other than lymphoma and nonmelanoma skin cancers (NMSC) include breast cancer, colon cancer, lung cancer, melanoma, and prostate cancer at a rate of $0.6(95 \% \mathrm{CI}$ $0.3,1.0) / 100$ PYs in 3853 adalimumab (Humira)-treated patients for a median duration of 5.5 months versus 0.4 (95\% CI 0.2, 1.0)/100 PYs in 2183 controls for a medical duration of 3.9 months. However, based on a recent pooled estimate from 23,458 patients treated with adalimumab on comparison with age- and sex-matched populations, the observed number of malignancies in each disease population was reported to be similar to the expected number in the reference population. ${ }^{27}$ The rates for lymphomas $\left(0.1 / 100\right.$ PYs) and NMSC (0.2/100 PYs) were very low. ${ }^{27}$ Some of the common side effects include injection site pain and reaction, hypersensitivity, and gastrointestinal disturbances. In contrast, rare adverse effects result in the reactivation of latent tuberculosis, autoantibody production leading to a lupus-like syndrome, blood dyscrasias, congestive cardiac failure, and interstitial lung diseases. ${ }^{28}$ Humira comes under category B for its use in pregnancy as animal studies have proven to be safe but controlled studies in humans are lacking. ${ }^{14}$ Its use in lactation is based on the benefit-risk ratio as decided by the doctor because it is unknown if adalimumab is excreted in breast milk or absorbed systemically. ${ }^{14}$ Its use in children has not been evaluated, and it should be used judiciously in geriatric population as there is already an increased risk of infections and malignancies in elderly. ${ }^{14}$

\section{Certolizumab pegol (Cimzia ${ }^{\circledR}$ )}

Mechanism of action and indications

Certolizumab pegol is a monoclonal antibody (MAb) manufactured by Union Chimique Belge (UCB) Pharmaceuticals (Brussels, Belgium) and subsequently approved by the FDA in April 2008 for $\mathrm{CD} .{ }^{29}$ Certolizumab pegol is a recombinant antigen-binding fragment (Fab) antibody against TNF- $\alpha$, which is conjugated to $40 \mathrm{kDa}$ polyethylene glycol, thereby enhancing the bioavailability, drug stability, and plasma half-life. ${ }^{30}$ The molecular mass of the Fab antibody frag- ment alone is $47.8 \mathrm{kDa}$. It is the only crystallizable fragment $(\mathrm{Fc})$-free PEGylated TNF- $\alpha$ inhibitor, so it does not fix complement or cause antibody-dependent cell-mediated cytotoxicity. ${ }^{30}$ The FDA-approved indications are moderateto-severely active CD or RA, active psoriatic arthropathy, and ankylosing spondylitis. ${ }^{29}$ It is available as powdered reconstitution form, which contains $200 \mathrm{mg}$ of sterile, white, lyophilized powder, and as prefilled syringe, which is a single-use, $1 \mathrm{~mL}$ prefilled glass syringe with a fixed $25 \mathrm{G}$ $1 / 2$ in thin wall needle, providing a dose of $200 \mathrm{mg} / 1 \mathrm{~mL} .{ }^{29}$ Upon single SC dose or intravenous (IV) dose, there was a predictable dose-related plasma concentration. There is a linear relationship between the dose given and the maximum plasma concentration $\left(\mathrm{C}_{\max }\right)$ and the area under the curve over time. Though metabolism studies have not been performed in humans, animal studies suggest that polyethylene glycol polymers are excreted unchanged in urine and the terminal plasma half-life is $\sim 14$ days. ${ }^{29}$

\section{Dosing in CD}

The recommended regimen in $\mathrm{CD}$ is the $\mathrm{SC}$ administration of $400 \mathrm{mg}$ initially and at weeks 2 and 4 . If there is response, $400 \mathrm{mg}$ SC is given once in every 4 weeks for maintenance. ${ }^{29}$ The efficacy of certolizumab is proven by the PRECiSE- 1 study, which was an RCT done at 171 sites where 331 patients with moderate-to-severe $\mathrm{CD}$ were randomized to receive $400 \mathrm{mg}$ certolizumab and 328 patients received placebo. At week 6, clinical response (100-point reduction in CDAI score) was $35 \%$ when compared with $27 \%$ in the placebo group $(P=0.02)$. At week 26 , the clinical remission (CDAI $\leq 150$ points) was $29 \%$ in the certolizumab group versus $18 \%$ in the placebo group $(P<0.05) .{ }^{31}$ Fistula closure rates were same at short term and long term with certolizumab when compared with placebo. ${ }^{31}$ PRECiSE-2 study evaluated patients who had clinical response with certolizumab at week 6 and were randomized to receive certolizumab $400 \mathrm{mg}(\mathrm{n}=216)$ or placebo $(\mathrm{n}=212)$ every 4 weeks over weeks 8-24 for maintenance therapy. The remission rates were $48 \%$ and $29 \%$, respectively, at week $26 .{ }^{32}$ Patients completing PRECiSE-1 and -2 received open-label certolizumab $400 \mathrm{mg}$ every 4 weeks for 7 years in PRECiSE-3 trial, and the clinical remission rate was $\geq 68 \%$ at each year based on observed cases..$^{33}$ Patients who relapsed in PRECiSE-1 and PRECiSE-2 received certolizumab re-induction followed by $400 \mathrm{mg}$ every 4 weeks maintenance for 360 weeks and the overall remission rates at weeks 52, 156, and 362 were $64 \%, 64 \%$, and $85 \%$, respectively, based on observed cases. ${ }^{34}$ WELCOME trial with 539 patients either intolerant or poor 
responders to infliximab, which was given open-label induction, showed $62 \%$ response rates and $39.3 \%$ remission rates, despite being a difficult-to-treat group. ${ }^{35}$

\section{Side effects}

The common adverse effects include injection site reactions and infections mainly of the respiratory tract and urinary tract; some of which can be very severe due to immune modulation. Similar to the other drugs in the class, reactivation of tuberculosis, hepatitis B, and malignancies have been reported, but hypersensitivity reactions are rare. ${ }^{36}$ Some of the other rare adverse effects reported in controlled trials are blood dyscrasias, optic neuritis, hepatitis, alopecia totalis, anxiety, bipolar disorder, suicidal tendencies, nephrotic syndrome, renal failure, menstrual disorders, and dermatitis. ${ }^{29}$ Certolizumab is a category B drug in pregnancy. Animal studies have proven no harm, but controlled human studies are not done. ${ }^{29}$ Because of its large molecular weight, it neither crosses the placental barrier nor gets secreted in the milk. Even if present in milk, the biologics would get degraded in the intestinal tract, but the local effect in the mucosa is not known. ${ }^{29}$ It is not recommended in pediatric use, and caution should be excised regarding its use in elderly due to the risk of malignancy and opportunistic infections. ${ }^{29}$

\section{Golimumab (Simponi ${ }^{\circledR}$ )}

\section{Mechanism of action and indications}

Golimumab is yet another fully human IgG1 kappa MAb first approved in 2009 by FDA for the treatment of RA. It was developed and marketed by Janssen Biotech, Inc (Horsham, PA, USA). ${ }^{37}$ It was isolated from a hybridoma clone produced by transgenic mice, which were immunized with human TNF$\alpha$. The commercial product, which is produced in a recombinant cell line culture, binds to the soluble and transmembrane forms of TNF- $\alpha$ and acts as an inhibitor. ${ }^{38}$ This agent has been approved for use in moderately to severely active RA, psoriatic arthritis, ankylosing spondylitis, and moderately to severely active UC. ${ }^{39}$ The European Medicines Agency has further approved it for JIA in combination with methotrexate for children $>40 \mathrm{~kg}$ body weight. ${ }^{40}$ It is available as prefilled glass syringes (27G $1 / 2 \mathrm{in}$ ) providing either $50 \mathrm{mg} / 0.5 \mathrm{~mL}$ or $100 \mathrm{mg} / 1 \mathrm{~mL}$ of solution. ${ }^{39}$ Upon SC administration, the bioavailability was $53 \%$ and gets primarily distributed in the circulatory system with limited extravascular distribution. ${ }^{39}$ The terminal plasma half-life is $\sim 2$ weeks, and the metabolic pathway is not known. ${ }^{39}$

\section{Dosing in UC}

The recommended dosage regimen for UC is $200 \mathrm{mg} \mathrm{SC}$ at week 0 followed by $100 \mathrm{mg}$ at week 2 and maintenance therapy $100 \mathrm{mg}$ once every 4 weeks. ${ }^{39}$ in the PURSUIT-SC, a Phase II/III multicenter, placebo-controlled, induction RCT, anti-TNF-naive patients with moderately to severely active UC were assigned randomly to receive placebo, or two golimumab regimens were given 2 weeks apart $(200 \mathrm{mg}$ followed by $100 \mathrm{mg}$ or $400 \mathrm{mg}$ followed by $200 \mathrm{mg}$ ). At week 6 , both the golimumab regimens induced significant clinical response (30 versus 51 and 55\%, both $P<0.0001$ ) and clinical remission (6 versus 18 and $18 \%$, both $P<0.0001) .{ }^{41}$ In the PURSUIT$\mathrm{M}$ RCT, patients in clinical response were randomized to receive either placebo or two regimens of golimumab (50 or $100 \mathrm{mg}$ every 4 weeks) for 52 weeks. At week 54, patients on golimumab achieved more continuous clinical response (31 versus 47 and 50\%, $P=0.01$ and $<0.001$ ) and remission (16 versus 23 and $28 \%, P=0.12$ and 0.004$).{ }^{42}$

\section{Side effects}

The common adverse events noted were infections and injection site reactions, which were similar in number to the placebo arm. ${ }^{43}$ Golimumab as the other TNF- $\alpha$ inhibitors can rarely cause severe infections, opportunistic infection, reactivation of tuberculosis, malignancies, heart failure, autoimmunity, and demyelinating disorders. ${ }^{43}$ It belongs to a category B drug in pregnancy as animal studies have shown no harm, but controlled human studies are lacking. ${ }^{39}$ The information regarding secretion into human milk, the effect on breastfed infant, or lactation is not known. ${ }^{39}$ Efficacy in children is not well established with one study on pediatric juvenile idiopathic arthritis demonstrating no efficacy but similar rate of adverse events when compared with adults. ${ }^{44}$ Caution should be exerted while using in elderly due to increased risk of infections and malignancy with increasing age. ${ }^{39}$

\section{Infliximab (Remicade ${ }^{\circledR}$ )}

Mechanism of action and indications

Infliximab is an engineered chimeric IgG1 MAb and created by combining mouse and human TNF that has increased the specificity and affinity to the TNF- $\alpha$ receptor. In 1988 at New York University's School of Medicine, this MAb against TNF has been discovered. ${ }^{45}$ Remicade was the first TNF- $\alpha$ blocking agent approved by the FDA, initially for treating $\mathrm{CD}$, in 1998. This is produced when the variable regions of a murine antibody (25\%) are fused with the constant regions of a human antibody (75\%) at the hinge region using genetic 
engineering. ${ }^{46}$ It is indicated for use in $\mathrm{CD}$ (pediatric and adult), UC (pediatric and adult), RA, ankylosing spondylitis, psoriatic arthritis, and plaque psoriasis. ${ }^{47}$ The agent is supplied as a sterile, white, lyophilized $100 \mathrm{mg}$ powder for IV infusion in a $20 \mathrm{~mL}$ vial. Each single-dose vial contains infliximab (100 mg), dibasic sodium phosphate dihydrate $(6.1 \mathrm{mg})$, monobasic sodium phosphate, monohydrate $(2.2 \mathrm{mg})$, polysorbate $80(0.5 \mathrm{mg})$, and sucrose $(500 \mathrm{mg})$ and no preservatives. ${ }^{47}$ In adults, single IV infusion of 3-20 mg/ $\mathrm{kg}$ showed a linear relationship between the dose that was administered and the maximum serum concentration. ${ }^{47}$ It acts by inhibiting the binding of TNF- $\alpha$ with its receptors. This results in the induction of proinflammatory cytokines such as IL-1 and IL-6. This causes an enhancement of leukocyte migration by increasing endothelial layer permeability and the expression of adhesion molecules by endothelial cells and leukocytes and results in the activation of neutrophil and eosinophil functional activities and the induction of acute-phase reactants and other liver proteins, as well as tissue-degrading enzymes produced by synoviocytes and/or chondrocytes. ${ }^{47}$ Infliximab does not neutralize TNF- $\beta$, and the median terminal half-life of infliximab is 7.7-9.5 days. ${ }^{47}$

\section{Dosing in $C D$ and $U C$}

The recommended dose is $5 \mathrm{mg} / \mathrm{kg}$ at 0,2 , and 6 weeks, which is followed by the maintenance regimen of $5 \mathrm{mg} / \mathrm{kg}$ every 8 weeks after that for the treatment of $\mathrm{CD}$ or $\mathrm{UC}$ in both adults and children. ${ }^{47}$ For adult patients with $\mathrm{CD}$ who respond and then lose their response, consideration may be given to treatment with $10 \mathrm{mg} / \mathrm{kg}{ }^{47} \mathrm{In}$ the Targan study, $65 \%$ of patients with active $\mathrm{CD}$ had a clinical response at weeks to doses 5,10 , and $20 \mathrm{mg} / \mathrm{kg}$ versus $17 \%$ for placebo with no dose-response effect. The remission rates were 33 versus 4\%. In the ACCENT- 1 trial with 573 patients and dose of $5 \mathrm{mg} / \mathrm{kg}, 58 \%$ achieved a clinical response and $28 \%$ achieved remission at week 2 . It was also found that three loading doses at weeks 0,2 , and 6 had significantly higher response rate at week 10 when compared with a single infusion at week 0 (69 versus $59 \%, P=0.035) .{ }^{48}$ In the ACCENT-1 maintenance trial, all patients received an induction dose of $5 \mathrm{mg} / \mathrm{kg}$ infliximab IV and then they were randomized to receive placebo or infliximab two doses ( 5 or $10 \mathrm{mg} / \mathrm{kg}$ ) for 1 year once every 8 weeks. The proportion of patients who had remission at 2 weeks and continued to be in remission at 30 weeks was $21 \%, 44 \%$, and $45 \% .{ }^{49}$ The evidence for the usefulness of infliximab in UC was mainly by two RCTs namely ACT-1 and ACT- $2 .{ }^{50}$ In ACT-1, $69 \%$ and $62 \%$ of patients who received infliximab 5 and $10 \mathrm{mg} / \mathrm{kg}$, respectively, at weeks 0,2 , and 6 , had desired clinical response at week 8 , in comparison to $37 \%$ of those receiving placebo ( $P<0.002$ for both comparisons $).{ }^{51}$ In ACT-2, $65 \%$ and $69 \%$ of patients who received infliximab 5 and $10 \mathrm{mg} / \mathrm{kg}$, respectively, achieved a clinical response at week 8 , when compared with $26 \%$ of those receiving placebo $\left(P<0.001\right.$ for both comparisons). ${ }^{52}$ A study done by Cote-Daigneault et al has shown the evidence for efficacy in fistulizing $\mathrm{CD}$ and achieving mucosal healing in $\mathrm{CD}$ unlike certolizumab and in UC. ${ }^{23}$

\section{Side effects}

The main adverse effect includes the development of antibodies that may lead to the loss of response, infusion reactions, and serum sickness-like reactions. ${ }^{50}$ Problems associated with immunomodulation as easy susceptibility to infections, reactivation of tuberculosis, certain malignancies, and opportunistic infections are similar as in other TNF- $\alpha$ inhibitors. ${ }^{50}$ There have also been reports of hepatitis, CNS vasculitis, and hematological derangements that have been reported with the use of infliximab. ${ }^{47}$ This agent belongs to category B in pregnancy, and its effect on a lactating infant or its presence in human milk is not known. However, as in other IgG antibodies, it is present in the placenta and the new born may face difficulties with immune suppression. ${ }^{47}$ Its safety and efficacy has been well established in children older than 6 years for use in UC and CD. Use of infliximab in elderly is advised with caution due to an otherwise increased risk of malignancy and infections. ${ }^{47}$

\section{Integrin receptor antagonists Vedolizumab (Entyvio)}

\section{Mechanism of action and indications}

Vedolizumab is a humanized MAb, which was approved by the FDA in July 2014 after a priority review. It is essentially an integrin $\alpha 4 \beta 7$ receptor antagonist, which blocks the binding of Mucosal Addressin Cell Adhesion Molecule-1 (MAdCAM-1) to the integrin receptor, thereby producing anti-inflammatory action by preventing T-cell adhesion and infiltration. ${ }^{53}$ Since integrin $\alpha 4 \beta 7$ receptors are found more in the gut epithelium, vedolizumab is indicated currently for moderate-to-severe $\mathrm{CD}$ and UC. ${ }^{54}$ Clinical trials in pediatric population are also ongoing for UC and CD since November 2017. ${ }^{55,56}$ The agent is available in the market as $300 \mathrm{mg}$ of lyophilized cake in a single-dose $20 \mathrm{~mL}$ vial for reconstitution. ${ }^{57}$ The plasma half-life is $\sim 25$ days. The drug undergoes a rapid, saturable, and nonlinear elimination at low concentration and a slower, linear, and nonspecific elimination at therapeutic or higher concentration. ${ }^{57}$ 


\section{Dosing in CD and UC}

Vedolizumab is given as a $300 \mathrm{mg}$ IV infusion at 0,2 , and 6 weeks and then every 8 weeks after that, for both UC and CD. If no improvement is noticed, the drug is withdrawn. ${ }^{57}$ In the GEMINI I induction therapy trial, 374 UC patients received either vedolizumab $300 \mathrm{mg}(\mathrm{n}=224)$ or only placebo $(\mathrm{n}=149)$ IV at weeks 0 and 2 . The rates of clinical response (47\% versus $26 \%$ ) and clinical remission (17\% versus $5 \%$ ) at week 6 were statistically significant $\left(P<0.001\right.$ for both). ${ }^{58}$ Those with clinical response at week 6 were randomized to receive vedolizumab $300 \mathrm{mg}$ IV every 4 weeks, or every 8 weeks or placebo for 52 weeks. The rates of clinical remission were $45 \%$ for the vedolizumab 4 -weekly group, $52 \%$ for the vedolizumab 8 -weekly group, and $16 \%$ for the placebo group $(P<0.001) .{ }^{58}$ The CD trials included the GEMINI II and GEMINI III, which showed mixed results of efficacy. ${ }^{59}$ At week 6 in GEMINI II RCT, clinical remission was seen in $14.5 \%$ who received vedolizumab and $6.8 \%$ who received placebo and clinical response was seen in $31.4 \%$ who received vedolizumab and $25.7 \%$ who received placebo $(P=0.23)$. Among patients who responded to induction therapy, $39.0 \%$ and $36.4 \%$ of those who received vedolizumab 8 - and 4-weekly, respectively, were in clinical remission at week $52 \%$ versus $21.6 \%$ of those who received placebo $(P<0.001$ and 0.004 , respectively, for the two vedolizumab groups versus placebo). ${ }^{60}$ GEMINI III trial was conducted in patients with TNF antagonist failure, and the remission rates at week 10 were $26.6 \%$ in vedolizumab group versus $12.1 \%$ in placebo group (nominal $P=0.001$ ). The response rates at week 6 were $39.2 \%$ versus $22.3 \%$, respectively (nominal $P=0.001$ ). ${ }^{61}$

\section{Side effects}

The most common adverse reactions seen with vedolizumab are infusion reactions and infections due to immunomodulation. ${ }^{54}$ Safety data showed a similar adverse reaction rate to placebo. ${ }^{55}$ Malignancies were reported in $0.4 \%$ of those treated with vedolizumab, but the long-term exposure was limited. ${ }^{57}$ A potential for immunogenicity was found with $13 \%$ of the patients treated showing antivedolizumab antibodies at 24 weeks. ${ }^{57}$ Safety and effectiveness in the pediatric population have not been established, while in geriatric population, no difference in safety and efficacy has been observed compared to the adult population. ${ }^{57}$ Till date, no studies have been done with this drug in pregnant women and it is rated a category B drug. ${ }^{57}$ No fetal harm was observed in studies done on rabbits and monkeys even at 20 times the recommended human dosage.$^{57}$ Animal studies detected vedolizumab in the milk of lactating monkeys, but it is still unknown whether it can be generalized to humans. Hence, the drug should be used with caution in nursing mothers. ${ }^{57}$

\section{Natalizumab (Tysabri ${ }^{\circledR}$ ) \\ Mechanism of action and indications}

Natalizumab, the first among its drug family, is a humanized IgG4 MAb against the $\alpha 4$ chains of integrins and behaves as a selective adhesion molecule antagonist inhibiting the translocation of leukocytes across blood vessel membranes approved by FDA in year $2004 .{ }^{62}$ The agent is nonspecific to antagonize $\alpha 4 \beta 1$ integrin (very late antigen [VLA]-4) and the $\alpha 4 \beta 7$ integrin (lymphocyte Peyer's patch adhesion molecule [LPAM]-1). ${ }^{63}$ VLA-4 is involved in regulating the trafficking of mononuclear leukocytes from the peripheral circulation to sites of inflammation, and this mechanism is tapped to treat multiple sclerosis. ${ }^{63}$ The only other indication of use is in CD, and the mechanism of action is similar to vedolizumab. ${ }^{63} \mathrm{It}$ is available as $300 \mathrm{mg}$ natalizumab in $15 \mathrm{~mL}(20 \mathrm{mg} / \mathrm{mL}) \mathrm{IV}$ solution in a sterile, single-use vial with no preservatives. ${ }^{64}$ Upon administration, the number of circulating leukocytes of all types is increased except the absolute neutrophil count. ${ }^{64}$ The mean half-life was $\sim 10-11$ days, and a steady state concentration after a 4-weekly dose was achieved at 24 weeks. ${ }^{64}$

\section{Dosing in CD}

The recommended dose in CD is $300 \mathrm{mg}$ IV infusion over 1 hour 4-weekly, and the agent was discontinued at 12 weeks if no response. It should not be used with concomitant immunosuppressants (eg, 6-mercaptopurine, azathioprine, cyclosporine, and methotrexate) or concomitant inhibitors of TNF- $\alpha .{ }^{64}$ ENACT-1 trial with 905 adult patients with moderate-to-severe disease across 142 global centers proved the efficacy of natalizumab in CD. Patients randomly received $300 \mathrm{mg}$ natalizumab 4-weekly $(\mathrm{n}=721)$ or placebo $(\mathrm{n}=181)$, and clinical response at week 10 was $56 \%$ versus $49 \%(P=0.05)$, respectively, while remission was seen in $37 \%$ versus $30 \%(P=0.12)$, respectively. ${ }^{65}$ Those with clinical response at week 10 underwent the maintenance phase for 52 weeks, and the sustained response was $61 \%$ versus $28 \%$ in placebo $\operatorname{arm}(P<0.0001) .{ }^{65}$ The next landmark trial was the ENCORE trial where 509 adult patients were randomized to receive natalizumab or placebo. At week 12, the clinical response rate was $60 \%$ versus $44 \%(P=0.001)$ and the remission rates were $38 \%$ versus $25 \%(P=0.001)$, respectively. ${ }^{66}$

\section{Side effects}

The most common adverse effects encountered are a headache, abdominal pain, joint pain, colitis including worsen- 
ing of $\mathrm{CD}$, influenza syndrome, infection, gastrointestinal disturbances, fatigue, pharyngitis, and infusion reaction. ${ }^{67}$ The serious adverse reactions as listed by the FDA include progressive multifocal leukoencephalopathy due to infection with John Cunningham virus, Herpes infections, hepatotoxicity, hypersensitivity, antibody formation, and immunosuppression. ${ }^{64}$ Natalizumab is a category B drug in pregnancy with detection in human milk as well, though its effect on a breastfed infant is unknown. ${ }^{64}$ It is not recommended for use in children, and sufficient data are not available to identify difference in responses among elderly. ${ }^{64}$

\section{IL- 12 and IL-23 antagonist Ustekinumab (Stelara ${ }^{\circledR}$ ) \\ Mechanism of action and indications}

Ustekinumab is a human IgGIא MAb against the p40 subunit of IL-12 and IL-23 cytokines. It was first approved in Canada in 2008 for the treatment of plaque psoriasis in adult patients and later in 2009 by FDA. ${ }^{68}$ IL-12 and IL-23 play an important role in the activation and differentiation of natural killer cells and $\mathrm{CD}^{+} \mathrm{T}$ lymphocytes. Hence, blocking their action helps in chronic inflammatory conditions such as plaque psoriasis, psoriatic arthritis, and $\mathrm{CD} .{ }^{69} \mathrm{It}$ is available as IV $130 \mathrm{mg} / 26 \mathrm{~mL}(5 \mathrm{mg} / \mathrm{mL})$ solution in a single-dose vial and SC $45 \mathrm{mg} / 0.5 \mathrm{~mL}$ or $90 \mathrm{mg} / \mathrm{mL}$ solution in a singledose prefilled syringe or $45 \mathrm{mg} / 0.5 \mathrm{~mL}$ in a single-dose vial. ${ }^{70}$ Treatment has been shown to decrease the expression of mRNA of IL-12 and IL-23. Steady-state concentrations are achieved by week 28 , and the mean elimination plasma half-life ranges from 15 to 45.5 days. ${ }^{70}$

\section{Dosing in $C D$}

The recommended dosage regimen is a single IV dose, which is weight based ( $260 \mathrm{mg}$ if weight is $\leq 55 \mathrm{~kg}, 390 \mathrm{mg}$ if weight is $>55-85 \mathrm{~kg}$, and $520 \mathrm{mg}$ if weight is $>85 \mathrm{~kg}$ ) followed by a maintenance dose of SC $90 \mathrm{mg}$ administered 8-weekly. ${ }^{70}$

The safety and efficacy of ustekinumab were evaluated in three randomized double-blind placebo-controlled clinical namely UNITI-1 and UNITI-2 for induction therapy and IM-UNITI for maintenance therapy. ${ }^{68}$ In the UNITI-1 trial $(\mathrm{n}=741)$, the clinical response rate at week 6 was $33.7 \%$ and $21.5 \%(P<0.01)$ and the remission rate at week 8 was $20.9 \%$ and $7.3 \%(P<0.001)$ in the ustekinumab and placebo arms, respectively. ${ }^{71}$ In the UNITI-2 trial $(n=628)$, the clinical response rate at week 6 was $55.5 \%$ and $28.7 \%(P<0.001)$ and the remission rate at week 8 was $40.2 \%$ and $19.6 \%(P<0.001)$ in the ustekinumab and placebo arms, respectively. ${ }^{71} \mathrm{IM}-$ UNITI trial testing ustekinumab $90 \mathrm{mg}$ SC maintenance 8-weekly and 12 -weekly, $53.1 \%$ and $48.8 \%$, respectively, were in clinical remission at week 44 when compared with $35.9 \%$ receiving placebo ( $P=0.005$ and 0.04 , respectively) ${ }^{72}$

\section{Side effects}

The most common adverse effects encountered were nasopharyngitis, injection site erythema, and vulvovaginal candidiasis besides other infections. Clinically significant and serious infections included anal abscess, gastroenteritis, and pneumonia ${ }^{69} \mathrm{~A}$ total of $0.2 \%$ of ustekinumab-treated patients and placebo-treated patients developed NMSC, whereas $0.2 \%$ of the ustekinumab-treated patients developed other cancers, which were none in the placebo group. ${ }^{70}$ Approximately $6 \%$ of the patients in the psoriasis studies developed antiustekinumab antibodies whereas only $3 \%$ of the patients in the CD studies did so. ${ }^{70}$ During the postmarketing phase, more incidents of hypersensitivity reactions such as anaphylaxis, angioedema, rashes, and urticaria have been reported. ${ }^{70}$ Human data on effects in pregnancy are not well established due to the lack of data. Animal studies have not shown any adverse developmental effects on the fetus even at doses $>100$ times the recommended human dose. ${ }^{70}$ Though studies in lactating monkeys have shown the presence of ustekinumab in the milk, no presence of the drug in human milk has been found. ${ }^{70}$ Safety and efficacy have not been established in the pediatric population, and there are no enough data among elderly to determine any difference in the safety and efficacy as compared to the adult population. ${ }^{70}$

\section{Biosimilars in IBD}

The treatment of IBD imposes a tremendous economic burden on the health care system as the cost utilization has seen a significant shift from hospitalization to medication, especially the biologics. ${ }^{73}$ With the patent period of many of these drugs coming to an end, it is possible to produce a similar biologics that could be marketed at a much lower price than the innovator biologics, some of which are already available in developing countries such as India and developed countries such as South Korea. ${ }^{74}$ These drugs are called as biosimilars, which may be defined as a biologic product that is highly like the reference biologic with no clinically meaningful differences in clinical safety or efficacy. ${ }^{75}$ Biologics are a highly complex protein or other substances derived from a biological source, and hence, complete reproducibility of reference biologics is not possible. Thus, minor differences in clinically inactive components are permissible. ${ }^{76}$ The current biosimilars approved for use in IBD belong to TNF- $\alpha$ inhibitors namely 
adalimumab and infliximab. ${ }^{77}$ Biosimilars of adalimumab include adalimumab-atto (Amjevita ${ }^{\mathrm{TM}}$ ) by Amgen Pharmaceuticals (Thousand Oaks, CA, USA) and adalimumababdm $\left(\right.$ Cyltezo $\left.^{\circledR}\right)$ by Boehringer Ingelheim. Amjevita was created using recombinant DNA technology in a mammalian cell expression system resulting in an antibody with human IgG1:k constant regions and human-derived heavy- and light-chain variable regions. It was approved by FDA in September 2016. ${ }^{78}$ Cyltezo is again a recombinant human IgG1 MAb, which was approved in August 2017. ${ }^{79}$ The indications of these two agents are similar to Humira except in hidradenitis suppurativa and uveitis in the same dosage regimen with similar efficacy and side effects. ${ }^{78,79}$

With regard to infliximab, there are again three biosimilars, which are approved by FDA namely infliximab-dyyb (Inflectra ${ }^{\circledR}$ ) by Pfizer (New York City, NY, USA), infliximababda (Renflexis ${ }^{\text {TM}}$ ) by Samsung Bioepis (Seoul, South Korea), and infliximab-qbtx (Ixifi'T) by Pfizer in 2016, 2017, and 2017, respectively. ${ }^{80-82}$ Both chimeric IgG1 $\kappa$ MAb composed of human constant and murine variable regions, which are produced by a recombinant cell line cultured. ${ }^{80,81}$ These agents are used in the same indications as Remicade at same dose with similar efficacy and adverse effects. ${ }^{80,81}$

\section{Future paradigm}

Biologics off late as mentioned has become an important modality of treatment in IBD and the mainstay of therapy in patients with fistulizing or perianal CD. ${ }^{83}$ However, the available treatment has certain drawbacks, the most important of which is $30 \%$ primary nonresponders. ${ }^{84}$ Some patients transiently show response but then experience a loss of response (secondary nonresponders). ${ }^{85}$ Besides this, the available agents come with a myriad of serious adverse effects such as antibody formation, malignancies, reactivation of tuberculosis and hepatitis B as mentioned. Therefore, there is a need to develop newer agents that are more effective with fewer side effects and agents with novel targets and novel mechanisms of action. Some of these novel targets include Janus kinase inhibitors (eg, tofacitinib), IL inhibitors, antisense oligonucleotides (eg, mongersen), sphingosine-1-phosphate (S1P) receptor agonist (eg, ozanimod), anti-integrin inhibitors, and so on. ${ }^{86}$ Janus kinase inhibitors interfere with the signaling pathway that is needed for inflammatory process, whereas the antisense oligonucleotides prevent translation process by binding to mRNA from which the protein is usually synthesized. ${ }^{87,88} \mathrm{~S} 1 \mathrm{P}$ receptor agonists decrease the total lymphocyte count in circulation, especially $\mathrm{CD} 4^{+} \mathrm{CCR} 7^{+}$and $\mathrm{CD}^{+}{ }^{+} \mathrm{CR} 7^{+} \mathrm{T}$ cells. ${ }^{89}$

\section{Conclusion}

As the burden of IBD is increasing with time, so is the plethora of novel agents under development for its treatment. Initially, biologics were prescribed much later in the course of the disease, but this paradigm has changed with the increasing availability of evidence that suggests early use of biological agents. Also, the focus of treatment has shifted from mere supportive or symptomatic to more therapeutic or curative. One of the significant hurdles faced currently with these newer biologics is the cost and adverse reactions. With the availability of biosimilars in the market now, the cost has come down drastically, and in the future with novel agents in the pipeline, one could expect to see agents with enhanced safety and tolerability.

\section{Author contributions}

All authors contributed toward data analysis, drafting and critically revising the paper and agree to be accountable for all aspects of the work.

\section{Disclosure}

The authors report no conflicts of interest in this work.

\section{References}

1. Machado MA, Maciel AA, de Lemos LL, et al. Adalimumab in rheumatoid arthritis treatment: a systematic review and meta-analysis of randomized clinical trials. Rev Bras Reum. 2013;53(5):419-430.

2. HUMIRA $^{\circledR}$ (adalimumab)Injection [package insert]. North Chicago, IL: AbbVie Inc. 2017.

3. Ng SC, Shi HY, Hamidi N, et al. Worldwide incidence and prevalence of inflammatory bowel disease in the 21 st century: a systematic review of population-based studies. Lancet. 2017;390(10114):2769-2778.

4. Ordás I, Eckmann L, Talamini M, Baumgart DC, Sandborn WJ. Ulcerative colitis. Lancet. 2012;380(9853):1606-1619.

5. Ott C, Schölmerich J. Extraintestinal manifestations and complications in IBD. Nat Rev Gastroenterol Hepatol. 2013;10(10):585-595.

6. Kornbluth A, Sachar DB; Practice Parameters Committee of the American College of Gastroenterology. Ulcerative colitis practice guidelines in adults: American College of Gastroenterology, Practice Parameters Committee. Am J Gastroenterol. 2010;105(3):501-523.

7. National Institute for Health and Clinical Excellence [webpage on the Internet]. Crohn's Disease: Management in Adults, Children and Young People. London: Royal College of Physicians (UK), National Clinical Guideline Centre. 2012 [updated May 2016]. Available at: https://www. nice.org.uk/guidance/cg152. Accessed January 27, 2018.

8. Zhang Y-Z, Li Y-Y. Inflammatory bowel disease: pathogenesis. World $J$ Gastroenterol. 2014;20(10):91-99.

9. Wallace JL, Sharkey KA. Pharmacotherapy of Inflammatory Bowel Disease. In: Brunton LL, Chabner B, Knollmann BC, editors. Goodman and Gilman's the Pharmacologic Basis of Therapeutics. 12 ed. New York, NY: McGraw-Hill; 2011:1351-54.

10. Brunton LL, Hilal-Dandan R, Knollman BC. Goodman \& Gilman's The Pharmacological basis of Therapeutics. 13th ed. New York, NY: McGraw-Hill; 2018:945-954.

11. D'Haens GR, Sartor RB, Silverberg MS, Petersson J, Rutgeerts P. Future directions in inflammatory bowel disease management. JCrohns Colitis. 2014;8(8):726-734. 
12. Morrow T, Felcone LH. Defining the difference: what makes biologics unique. Biotechnol Healthc. 2004;1(4):24-26,28-29.

13. Chan HC, Ng SC. Emerging biologics in inflammatory bowel disease. $J$ Gastroenterol. 2017;52(2):141-150.

14. FDA. Humira (adalimumab): Prescribing information; 2012; 1-73. Available from: http://www.rxabbvie.com/pdf/humira.pdf. Accessed March 13, 2018.

15. AbbVie - Pharmaceutical Products. Available from: https://www.abbvie. com/our-science.html. Accessed February 4, 2018.

16. Kempeni J. Preliminary results of early clinical trials with the fully human anti-TNF $\alpha$ monoclonal antibody D2E7. Ann Rheum Dis. 1999;58:I70-I72.

17. Lapadula G, Marchesoni A, Armuzzi A, et al. Adalimumab in the treatment of immune-mediated diseases. Int J Immunopathol Pharmacol. 2014;27(1 suppl):33-48.

18. Lichtenstein GR, Panaccione R, Mallarkey G. Efficacy and safety of Adalimumab in Crohn's disease. Therap Adv Gastroenterol. 2008;1(1): $43-50$.

19. Hanauer SB, Sandborn WJ, Rutgeerts P, et al. Human anti-tumor necrosis factor monoclonal antibody (adalimumab) in Crohn's disease: the CLASSIC-I trial. Gastroenterology. 2006;130(2):323-333.

20. Sandborn WJ, Hanauer SB, Rutgeerts P, et al. Adalimumab for maintenance treatment of Crohn's disease: results of the CLASSIC II trial Gut. 2007;56(9):1232-1239.

21. Colombel JF, Sandborn WJ, Rutgeerts P, et al. Adalimumab for maintenance of clinical response and remission in patients with Crohn's disease: the CHARM trial. Gastroenterology. 2007;132(1):52-65.

22. Rutgeerts P, Sandborn WJ, Enns R, et al. Adalimumab rapidly induces clinical response and remission in patients with moderate to severe Crohn's disease who had secondary failure to infliximab therapy: results of the GAIN study. Gut. 2006;55(suppl):A20.

23. Côté-Daigneault J, Bouin M, Lahaie R, Colombel JF, Poitras P. Biologics in inflammatory bowel disease: what are the data? United European Gastroenterol J. 2015;3(5):419-428.

24. Hyams JS, Griffiths A, Markowitz J, et al. Safety and efficacy of adalimumab for moderate to severe Crohn's disease in children. Gastroenterology. 2012;143(2):365-374.

25. Faubion WA, Dubinsky M, Ruemmele FM, et al. Long-term efficacy and safety of Adalimumab in pediatric patients with Crohn's disease Inflamm Bowel Dis. 2017;23(3):453-460.

26. Chen X, Hou J, Yuan Y, et al. Adalimumab for moderately to severely active ulcerative colitis: a systematic review and meta-analysis. BioDrugs. 2016;30(3):207-217.

27. Burmester GR, Panaccione R, Gordon KB, McIlraith MJ, Lacerda AP. Adalimumab: long-term safety in 23458 patients from global clinical trials in rheumatoid arthritis, juvenile idiopathic arthritis, ankylosing spondylitis, psoriatic arthritis, psoriasis and Crohn's disease. Ann Rheum Dis. 2013;72(4):517-524.

28. Schiff MH, Burmester GR, Kent JD, et al. Safety analyses of adalimumab (HUMIRA) in global clinical trials and US post marketing surveillance of patients with rheumatoid arthritis. Ann Rheum Dis. 2006;65(7):889-894

29. FDA. Cimzia (certolizumab pegol) - Prescribing information. 2017; 1-40. Available from: https://www.accessdata.fda.gov/drugsatfda_docs/ label/2017/125160s270lbl.pdf. Accessed February 5, 2018.

30. FDA. Center for Drug Evaluation and Research. Application number: BLA 125160/0. Pharmacology review(s); 2008. Available from: http:// www.accessdata.fda.gov/drugsatfda_docs/nda/2008/125160s000_ PharmR_P1.pdf. Accessed February 5, 2018.

31. Sandborn WJ, Feagan BG, Sloinov S, et al. Certolizumab pegol for the treatment of Crohn's disease. N Engl J Med. 2007;357(3):228-238.

32. Schreiber S, Khaliq-Kareemi M, Lawrance IC, et al. Maintenance therapy with certolizumab pegol for Crohn's disease. $N$ Engl $J$ Med. 2007;357(3):239-250.

33. Sandborn WJ, Lee SD, Randall C, et al. Long-term safety and efficacy of certolizumab pegol in the treatment of Crohn's disease: 7-year results from the PRECiSE 3 study. Aliment Pharmacol Ther. 2014;40(8):903-916.
34. Lee SD, Rubin DT, Sandborn WJ, et al. Reinduction with certolizumab pegol in patients with Crohn's disease experiencing disease exacerbation: 7-year data from the PRECiSE 4 study. Inflamm Bowel Dis. 2016;22(8):1870-1880.

35. Sandborn WJ, Abreu MT, D'Haens G, et al. Certolizumab pegol in patients with moderate to severe Crohn's disease and secondary failure to infliximab. Clin Gastroenterol Hepatol. 2010;8(8):688-695.

36. Deeks ED. Certolizumab pegol: a review in inflammatory autoimmune diseases. BioDrugs. 2016;30(6):607-617.

37. Mazumdar S, Greenwald D. Golimumab. MAbs. 2009;1(5):422-431.

38. Strik AS, Berends SE, Mathôt RA, D'Haens GR, Löwenberg M. Golimumab for moderate to severe ulcerative colitis. Expert Rev Gastroenterol Hepatol. 2017;11(5):401-406.

39. FDA. Simponi (Golimumab) - Prescribing information. 2017;1-51. Available from: https://www.accessdata.fda.gov/drugsatfda_docs/ label/2015/125289s024lbl.pdf. Accessed February 5, 2018.

40. European Medicines Agency. Summary of Product characteristics. Available from: http://www.ema.europa.eu/docs/en_GB/document_library/ EPAR_-_Product_Information/human/000992/WC500052368.pdf. Accessed February 13, 2018.

41. Sandborn W, Feagan B, Marano C, et al. Subcutaneous golimumab induces clinical response and remission in patients with moderate-tosevere ulcerative colitis. Gastroenterology. 2014;146(1):85-95.

42. Sandborn W, Feagan B, Marano C, et al. Subcutaneous golimumab maintains clinical response in patients with moderate-to-severe ulcerative colitis. Gastroenterology. 2014;146(1):96-109.

43. Flamant M, Paul S, Roblin X. Golimumab for the treatment of ulcerative colitis. Expert Opin Biol Ther. 2017;17(7):879-886.

44. Brunner HI, Ruperto N, Tzaribachev N, et al; for the Paediatric Rheumatology International Trials Organisation (PRINTO) and the Pediatric Rheumatology Collaborative Study Group (PRCSG). Subcutaneous golimumab for children with active polyarticular-course juvenile idiopathic arthritis: results of a multicentre, double-blind, randomisedwithdrawal trial. Ann Rheum Dis. 2018;77:21-29.

45. Liang S, Dai J, Hou S, et al. Structural basis for treating tumor necrosis factor alpha (TNFalpha)-associated diseases with the therapeutic antibody infliximab. J Biol Chem. 2013;288(19):13799-13807.

46. de Ridder L, Benninga MA, Taminiau JA, Hommes DW, van Deventer SJ. Infliximab use in children and adolescents with inflammatory bowel disease. J Pediatr Gastroenterol Nutr. 2007;45(1):3-14.

47. FDA. Remicade (Infliximab) - Prescribing information; 2017;1-51. Available from: http://www.janssenlabels.com/package-insert/productmonograph/prescribing-information/REMICADE-pi.pdf.

48. Targan SR, Hanauer SB, van Deventer SJ, et al. A short-term study of chimeric monoclonal antibody cA2 to tumor necrosis factor alpha for Crohn's disease. Crohn's Disease cA2 Study Group. $N$ Engl J Med. 1997;337(15):1029-1035.

49. Hanauer SB, Feagan BG, Lichtenstein GR, et al. Maintenance infliximab for Crohn's disease: the ACCENT I randomised trial. Lancet. 2002;359(9317):1541-1549.

50. Rutgeerts P, Van Assche G, Vermeire S. Review article: infliximab therapy for inflammatory bowel disease - seven years on. Aliment Pharmacol Ther. 2006;23(4):451-463.

51. Rutgeerts P, Feagan BG, Olson A, Reinisch W, Olson A, Johannset J. A randomized placebo-controlled trial of infliximab therapy for active ulcerative colitis: act I trial. Gastroenterology. 2005;128:A-105.

52. Sandborn WJ, Rachmilewitz D, Hanauer SB, et al. Infliximab induction and maintenance therapy for ulcerative colitis: the Act 2 trial. Gastroenterology. 2005; 128:A-104.

53. Hesterberg PE, Winsor-Hines D, Briskin MJ, et al. Rapid resolution of chronic colitis in the cotton-top tamarin with an antibody to a gut-homing integrin alpha 4 beta 7. Gastroenterology. 1996;111(5):1373-1380.

54. Lau MS, Tsai HH. Review of vedolizumab for the treatment of ulcerative colitis. World J Gastrointest Pharmacol Ther. 2016;7(1):107-111.

55. clinicaltrials.gov. Vedolizumab IV in Pediatric Participants With Ulcerative Colitis (UC) or Crohn's Disease (CD). Available from: https://clinicaltrials.gov/ct2/show/NCT03138655. NLM identifier: NCT03138655. Accessed April 7, 2018. 
56. Long-term Safety IWith Vedolizumab IV in Pediatric Subjects With Ulcerative Colitis or Crohn's Disease. Available from: https://clinicaltrials.gov/ct2/show/NCT03196427. Accessed February 13, 2018.

57. FDA. Entyvio (Vedolizumab) - Prescribing information. 2017;1-21. Available from: https://www.accessdata.fda.gov/drugsatfda_docs/ label/2014/125476s000lbl.pdf. Accessed February 5, 2018.

58. Feagan BG, Rutgeerts PJ, Sands BE, et al. 943b Induction therapy for ulcerative colitis: results of GEMINI I, a randomised placebocontrolled, double-blind, multicentre phase 3 trial. Gastroenterology. 2012;142:S160-S161.

59. Garnock-Jones KP. Vedolizumab: a review of its use in adult patients with moderately to severely active ulcerative colitis or Crohn's disease. BioDrugs. 2015;29(1):57-67.

60. Sandborn WJ, Feagan BG, Rutgeerts P, et al. Vedolizumab as induction and maintenance therapy for Crohn's disease. $N$ Engl $J$ Med. 2013;369(8):711-721.

61. Sands BE, Feagan BG, Rutgeerts P, et al. Effects of vedolizumab induction therapy for patients with Crohn's disease in whom tumor necrosis factor antagonist treatment failed. Gastroenterology. 2014;147(3):618.e-627.e.

62. Gensicke H, Leppert D, Yaldizli O, et al. Monoclonal antibodies and recombinant immunoglobulins for the treatment of multiple sclerosis. CNS Drugs. 2012;26(1):11-37.

63. Zhang $\mathrm{Y}$, Wang $\mathrm{H}$. Integrin signalling and function in immune cells. Immunology. 2012;135(4):268-275.

64. FDA. Tysabri (Natalizumab) - Prescribing information; 2017;1-29. Available from: https://www.tysabri.com/content/dam/commercial/ multiple-sclerosis/tysabri/pat/en_us/pdfs/tysabri_prescribing_information.pdf. Accessed February 5, 2018.

65. Sandborn WJ, Colombel JF, Enns R, et al. Natalizumab induction and maintenance therapy for Crohn's disease. $N$ Engl $J$ Med. 2005;353(18):1912-1925.

66. Targan SR, Feagan BG, Fedorak RN, et al. Natalizumab for the treatment of active Crohn's disease: results of the ENCORE trial. Gastroenterology. 2007;132(5):1672-1683.

67. Guagnozzi D, Caprilli R. Natalizumab in the treatment of Crohn's disease. Biologics. 2008;2(2):275-284.

68. Lamb YN, Duggan ST. Ustekinumab: a review in moderate to severe Crohn's disease. Drugs. 2017;77(10):1105-1114.

69. European Medicines Agency [homepage on the Internet]. Stelara $130 \mathrm{mg}$ for solution for infusion: EU summary of product characteristics; 2017. Available from: http://www.ema.europa.eu/. Accessed February 5, 2018.

70. FDA. Stelara (Ustekinumab) - Prescribing information. 2016;1-37. Available from: https://www.accessdata.fda.gov/drugsatfda_docs/ label/2016/761044lbl.pdf. Accessed February 5, 2018.

71. Feagan BG, Sandborn WJ, Gasink C, et al. Ustekinumab as induction and maintenance therapy for Crohn's disease. $N$ Engl J Med. 2016;375(20):1946-1960.

72. Sandborn WJ, Gasink C, Gao LL, et al. Ustekinumab induction and maintenance therapy in refractory Crohn's disease. $N$ Engl J Med. 2012;367(16):1519-1528.
73. van der Valk ME, Mangen MJ, Leenders M, et al. Healthcare costs of inflammatory bowel disease have shifted from hospitalisation and surgery towards anti-TNFa therapy: results from the COIN study. Gut. 2014;63(1):72-79.

74. Wang J, Chow SC. On the regulatory approval pathway of biosimilar products. Pharmaceuticals. 2012;5(4):353-368.

75. FDA [webpage on the Internet]. Biosimilars. Available from: https:// www.fda.gov/Drugs/DevelopmentApprovalProcess/HowDrugsareDevelopedandApproved/ApprovalApplications/TherapeuticBiologicApplications/Biosimilars. Accessed January 30, 2018.

76. European Medicines Agency [webpage on the Internet]. Biosimilar medicines (similar biological medicinal products). Available from: http://www.ema.europa.eu/ema/index.jsp?curl=pages/medicines/ general/general_content_001832.jsp\&mid=WC0b01ac0580bb8fda. Accessed January 30, 2018.

77. Paramsothy S, Cleveland NK, Zmeter N, Rubin DT. The role of biosimilars in inflammatory bowel disease. Gastroenterol Hepatol. 2016;12(12):741-751.

78. FDA. Amjevita (Adalimumab - atto) - Prescribing information. 2016;161. Available from: https://www.accessdata.fda.gov/drugsatfda_docs/ label/2016/761024lbl.pdf. Accessed February 5, 2018.

79. FDA. Cyltezo (Adalimumab - abdm) - Prescribing information. 2017;1-38. Available from: https://www.accessdata.fda.gov/drugsatfda_docs/label/2017/761058lbl.pdf. Accessed February 5, 2018.

80. FDA. Inflectra (Infliximab - dyyb) - Prescribing information. 2016;156. Available from: https://www.accessdata.fda.gov/drugsatfda_docs/ label/2016/125544s000lbl.pdf. Accessed February 9, 2018.

81. FDA. Renflexis (Infliximab - abda) - Prescribing information. 2017;154. Available from: https://www.accessdata.fda.gov/drugsatfda_docs/ label/2017/761054Orig1s000lbl.pdf. Accessed February 9, 2018.

82. FDA. Ixifi (Infliximab-qbtx) - Prescribing information; 2017;1-37. Available from: https://www.accessdata.fda.gov/drugsatfda_docs/ label/2017/761072s000lbl.pdf. Accessed February 9, 2018

83. Ford AC, Sandborn WJ, Khan KJ, Hanauer SB, Talley NJ, Moayyedi P. Efficacy of biological therapies in inflammatory bowel disease: systematic review and meta-analysis. Am J Gastroenterol. 2011;106(4): 644-659.

84. Yanai H, Hanauer SB. Assessing response and loss of response to biological therapies in IBD. Am J Gastroenterol. 2011;106(4): 685-698.

85. Danese S, Vuitton L, Peyrin-Biroulet L. Biologic agents for IBD: practical insights. Nat Rev Gastroenterol Hepatol. 2015;12(9):537-545.

86. Sandborn WJ. The present and future of inflammatory bowel disease treatment. Gastroenterol Hepatol. 2016;12(7):438-441.

87. Adis Editorial. Tofacitinib. Drugs R\&D. 2010;10(4):271-284.

88. Chery J. RNA therapeutics: RNAi and antisense mechanisms and clinical applications. Postdoc J. 2016;4(7):35-50.

89. Juif PE, Kraehenbuehl S, Dingemanse J. Clinical pharmacology, efficacy, and safety aspects of sphingosine-1-phosphate receptor modulators. Expert Opin Drug Metab Toxicol. 2016;12(8):879-895.
Journal of Inflammation Research

\section{Publish your work in this journal}

The Journal of Inflammation Research is an international, peer-reviewed open access journal that welcomes laboratory and clinical findings on the molecular basis, cell biology and pharmacology of inflammation including original research, reviews, symposium reports, hypothesis formation and commentaries on: acute/chronic inflammation; mediators of

\section{Dovepress}

inflammation; cellular processes; molecular mechanisms; pharmacology and novel anti-inflammatory drugs; clinical conditions involving inflammation. The manuscript management system is completely online and includes a very quick and fair peer-review system. Visit http://www.dove press.com/testimonials.php to read real quotes from published authors. 